Article

\title{
One-Pot Catalytic Conversion of Cellobiose to Sorbitol over Nickel Phosphides Supported on MCM-41 and Al-MCM-41
}

\author{
Wipark Anutrasakda ${ }^{1} \mathbb{D}$, Kanyanok Eiamsantipaisarn $^{2}$, Duangkamon Jiraroj ${ }^{2}$, \\ Apakorn Phasuk ${ }^{2}$, Thawatchai Tuntulani ${ }^{2}$, Haichao Liu ${ }^{3}$ and \\ Duangamol Nuntasri Tungasmita $4, *$ D \\ 1 Green Chemistry for Fine Chemical Productions STAR, Department of Chemistry, Faculty of Science, \\ Chulalongkorn University, Payathai Road, Patumwan, Bangkok 10330, Thailand; wipark.a@chula.ac.th \\ 2 Department of Chemistry, Faculty of Science, Chulalongkorn University, Pathumwan, \\ Bangkok 10330, Thailand; kanyanok.e@gmail.com (K.E.); jiraroj_d@hotmail.com (D.J.); \\ apakorn.phasuk@gmail.com (A.P.); thawatchai.t@chula.ac.th (T.T.) \\ 3 College of Chemistry and Molecular Engineering, Peking University, Chengfu Road, Haidian, \\ Beijing 100871, China; hcliu@pku.edu.cn \\ 4 Center of Excellence in Catalysis for Bioenergy and Renewable Chemicals (CBRC), Department of Chemistry, \\ Faculty of Science, Chulalongkorn University, Pathumwan, Bangkok 10330, Thailand \\ * Correspondence: duangamol.n@chula.ac.th; Tel.: +66-2-218-7619
}

Received: 4 December 2018; Accepted: 15 January 2019; Published: 16 January 2019

check for updates

\begin{abstract}
MCM-41- and Al-MCM-41-supported nickel phosphide nanomaterials were synthesized at two different initial molar ratios of $\mathrm{Ni} / \mathrm{P}$ : 10:2 and 10:3 and were tested as heterogeneous catalysts for the one-pot conversion of cellobiose to sorbitol. The catalysts were characterized by X-ray diffractometer (XRD), N2 adsorption-desorption, scanning electron microscope (SEM), transmission electron microscope (TEM), ${ }^{27} \mathrm{Al}$-magnetic angle spinning-nuclear magnetic resonance spectrometer ( ${ }^{27} \mathrm{Al}$ MAS-NMR), temperature programmed desorption of ammonia $\left(\mathrm{NH}_{3}-\mathrm{TPD}\right)$, temperature-programmed reduction $\left(\mathrm{H}_{2}-\mathrm{TPR}\right)$, and inductively coupled plasma optical emission spectrophotometer (ICP-OES). The characterization indicated that nickel phosphide nanoparticles were successfully incorporated into both supports without destroying their hexagonal framework structures, that the catalysts contained some or all of the following Ni-containing phases: $\mathrm{Ni}^{0}, \mathrm{Ni}_{3} \mathrm{P}$, and $\mathrm{Ni}_{12} \mathrm{P}_{5}$, and that the types and relative amounts of $\mathrm{Ni}$-containing phases present in each catalyst were largely determined by the initial molar ratio of $\mathrm{Ni} / \mathrm{P}$ as well as the type of support used. For cellobiose conversion at $150{ }^{\circ} \mathrm{C}$ for $3 \mathrm{~h}$ under $4 \mathrm{MPa}$ of $\mathrm{H}_{2}$, all catalysts showed similarly high conversion of cellobiose (89.5-95.0\%). Nevertheless, sorbitol yield was highly correlated to the relative amount of phases with higher content of phosphorus present in the catalysts, giving the following order of catalytic performance of the Ni-containing phases: $\mathrm{Ni}_{12} \mathrm{P}_{5}>\mathrm{Ni}_{3} \mathrm{P}>\mathrm{Ni}$. Increasing the reaction temperature from $150{ }^{\circ} \mathrm{C}$ to $180{ }^{\circ} \mathrm{C}$ also led to an improvement in sorbitol yield (from $43.5 \%$ to $87.8 \%)$.
\end{abstract}

Keywords: nickel phosphide; cellobiose; sorbitol; MCM-41; hydrolytic hydrogenation

\section{Introduction}

The use of biomass as a renewable feedstock to produce fuels and chemicals has gained much attention due to the depletion of fossil fuels and global warming [1,2]. The most abundant biomass is lignocellulose, which is composed of cellulose, hemicellulose, and lignin. The proportion of the three components may differ between plants, but cellulose generally makes up the largest proportion [3]. 
Cellulose is a non-edible saccharide polymer containing glucose units linked together via $\beta-1,4$-glycosidic bonds. The intra- and intermolecular hydrogen bondings are formed within and between the cellulose chains, respectively. Due to its highly rigid structure, high crystallinity index, and insolubility in common solvents including water, the conversion of cellulose to valuable chemicals has been a challenge [4]. A number of attempts have been made regarding the use of catalysts to convert cellulose or cellobiose, a model compound of cellulose, to renewable feedstocks such as glucose [5], methyl glucosides [6], 5-HMF [7], gluconic acid [8], ethylene glycol [9] and sorbitol [10].

Sorbitol is one of the most industrially important renewable feedstocks; it is the most used sugar alcohol and has wide applications in food, pharmaceutical and cosmetic industries [11]. For instance, sorbitol is used as low-calorie sweetener, a component in toothpaste, and a feedstock for the production of vitamin C. Typically, sorbitol is commercially produced by the one-step catalytic hydrogenation of glucose [11]. Additionally, since glucose may be hydrolyzed from cellulose or cellobiose, many researches have investigated the two-step catalytic conversion of cellulose or cellobiose to sorbitol under hydrolytic hydrogenation [12-16]. A catalytic hydrolytic hydrogenation system for the conversion of cellulose or cellobiose to sorbitol normally requires two components: (i) soluble acid, such as phosphoric acid, or solid acid support, such as zeolite and acid-functionalized silica, for the catalytic hydrolysis of cellulose/cellobiose to glucose and (ii) noble transition metals, such as platinum, ruthenium, and palladium for the catalytic hydrogenation of glucose to sorbitol.

Catalytic systems based on nickel, a non-noble metal, have also been found to be efficient and cost effective for hydrogenation processes to produce sugar-related compounds [17-19]. It is therefore of interest to develop nickel-based catalysts that contain both acidic and metallic functions in order to accomplish the one-pot hydrolytic hydrogenation for the conversion of cellulose/cellobiose to sorbitol. One way to achieve such bifunctional properties is to form a compound between nickel and phosphorus, namely nickel phosphide. The presence of phosphorus would play an important role in creating Brönsted acid sites from P-OH groups [20]. Nickel phosphide catalysts are otherwise well known for their good catalytic activity in processes such as hydrodesulfurization (HDS) and hydrodenitrogenation (HDN) [21,22]. Furthermore, due to the fact that different stoichiometric ratios of nickel to phosphorus can lead to the formation of different phases of nickel phosphides [23,24], it is also of interest to investigate the bifunctional catalytic properties of different phases of nickel phosphide in the one-pot conversion of cellulose/cellobiose to sorbitol. The use of nickel phosphide nanoparticles as heterogeneous catalyst without support, however, may result in poor catalytic activity due primarily to particle aggregation. Support materials that can help improve the nanoparticle dispersion and therefore circumvent this problem include the widely used mesoporous MCM-41 and Al-MCM-41 materials, owing to their facile synthesis, high specific surface area, uniform pore size distribution, and ordered mesoporous channels $[25,26]$.

In the present study, we report the synthesis and full characterization of supported nickel phosphide catalysts prepared with two different ratios of nickel to phosphorus where MCM-41 and Al-MCM-41 were used as supports in order to enhance the dispersion of nickel phosphide nanoparticles. The synthesized catalysts were then tested for their bifunctional catalytic performance in the one-pot conversion of cellobiose to sorbitol. The catalytic performance of different phases of nickel phosphides was comparatively investigated. The effect of different supports on the formation of nickel phosphide phases and on the catalytic performance was also studied.

\section{Results and Discussion}

\subsection{Characterization of the Catalysts}

The low-angle XRD patterns $\left(2 \theta=1.5^{\circ}-6.0^{\circ}\right)$ are shown in Figure $1 \mathrm{a}, \mathrm{b}$. At low angles, the XRD patterns of MCM-41 and Al-MCM-41 samples exhibited a sharp peak at $2 \theta \approx 2.3^{\circ}$, and two small peaks at $2 \theta \approx 3.9^{\circ}$ and $4.5^{\circ}$, which could be indexed as the (100), (110), and (200) planes, respectively [25]. This finding indicates that both samples exhibited hexagonal structure with a high degree of structural 
ordering. After nickel phosphide doping, the XRD patterns of the M-xNiyP and Al-M-xNiyP samples exhibited similar characteristics to those of the undoped counterparts, indicating that the incorporation of nickel phosphide nanoparticles into the mesoporous structures of MCM-41 and Al-MCM-41 did not destroy the underlying framework structure of the supports. Nevertheless, the XRD peaks of the $\mathrm{M}-\mathrm{xNiyP}$ and Al-M-xNiyP samples were less intense and slightly shifted to higher angles, suggesting a decrease in their lattice parameters with respect to those of the undoped counterparts.
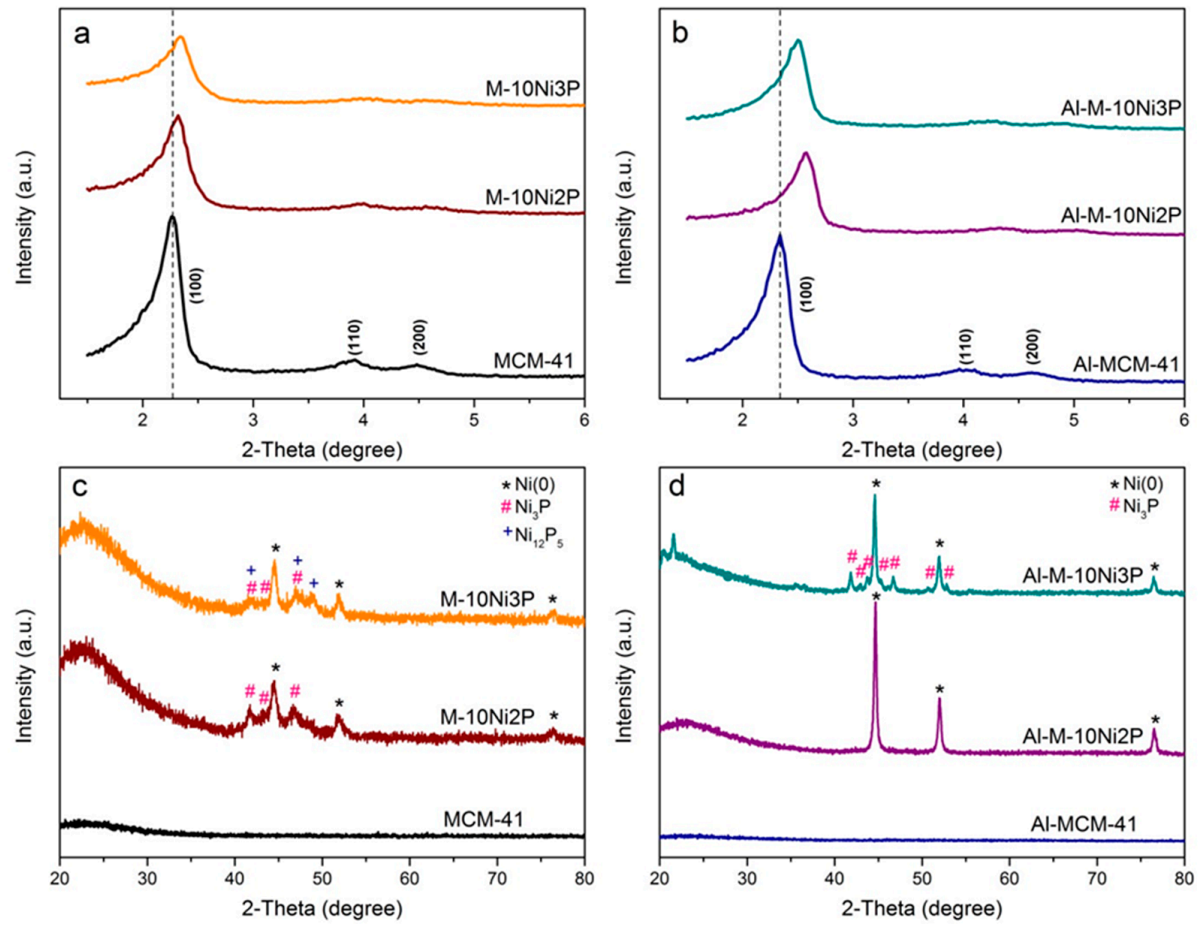

Figure 1. X-ray diffraction patterns of the synthesized materials at low angles (a-b) and high angles (c-d).

The high-angle XRD patterns $\left(2 \theta=20^{\circ}-80^{\circ}\right)$ of the modified materials are shown in Figure $1 \mathrm{c}, \mathrm{d}$. At high angles, a broad peak at $2 \theta \approx 23^{\circ}$ was observed for all $\mathrm{M}$-xNiyP and Al-M-xNiyP samples, which could be attributed to amorphous silica. Furthermore, the XRD results indicate that various phases of nickel phosphides were present in the modified samples and that the initial Ni/P molar ratio played a significant role in determining the proportion of each nickel phosphide phase in each sample. In particular, when the initial Ni/P molar ratio of the modified samples in each series was decreased from 10:2 to 10:3, a new phase with lower relative contents of $\mathrm{Ni}$ was present. For instance, the XRD result of the M-10Ni2P sample showed two sets of peaks ascribable to the $\mathrm{Ni}^{0}$ phase (JCPDS No. 89-7128; $2 \theta \approx 44.3^{\circ}, 51.7^{\circ}$, and $76.1^{\circ}$, corresponding to (111), (200), and (220) planes, respectively) and the $\mathrm{Ni}_{3} \mathrm{P}$ phase (JCPDS No. 34-0501; $2 \theta \approx 41.8^{\circ}, 43.6^{\circ}$, and $46.6^{\circ}$, corresponding to (321), (112), and (141) planes, respectively). On the other hand, when the initial Ni/P molar ratio of the M-xNiyP series samples was decreased to $10: 3$, the $\mathrm{Ni}_{12} \mathrm{P}_{5}$ phase (JCPDS No. 22-1190; $2 \theta \approx 41.6^{\circ}, 47.0^{\circ}$, and $49.0^{\circ}$, corresponding to (400), (240), and (312) planes, respectively) was also observed in addition to the two aforementioned phases.

Further analysis of the XRD results indicates that the type of support also had an effect on the obtained phases of nickel phosphides. Specifically, for each given initial Ni/P molar ratio, the use of Al-MCM-41 as support material was associated with a lesser presence of nickel phosphide phases as compared to when MCM-41 was used as support. For instance, only the crystalline phase of $\mathrm{Ni}^{0}$ was present in the XRD pattern of the Al-M-10Ni2P sample, while both $\mathrm{Ni}^{0}$ and $\mathrm{Ni}_{3} \mathrm{P}$ phases were present in the XRD pattern of the M-10Ni2P sample. These findings might be attributed to the relatively larger presence of unreduced phosphorus species such as $\mathrm{P}_{4} \mathrm{O}_{12}{ }^{4^{\mathrm{TM}}}$ that remained on the surface of the 
Al-MCM-41 support [27], hindering the production of phosphorus-rich nickel phosphide species on this type of support.

The $\mathrm{N}_{2}$ adsorption desorption isotherms of both pure and modified MCM-41 and Al-MCM-41 materials exhibited a type IV isotherm (Figure 2), which is a characteristic of mesoporous materials [28]. The textural properties of the prepared materials are reported in Table 1. The total BET surface areas of pure MCM-41 and Al-MCM-41 were 900 and $843 \mathrm{~m}^{2} \mathrm{~g}^{-1}$, respectively, which were significantly larger than those of the nickel phosphide doped counterparts. In particular, the BET surface areas of $\mathrm{M}-\mathrm{xNiyP}$ and Al-M-xNiyP materials were in the ranges of $577-771$ and $622-643 \mathrm{~m}^{2} \mathrm{~g}^{-1}$, respectively. This finding is consistent with the successful incorporation of nickel phosphide nanoparticles into both supports.

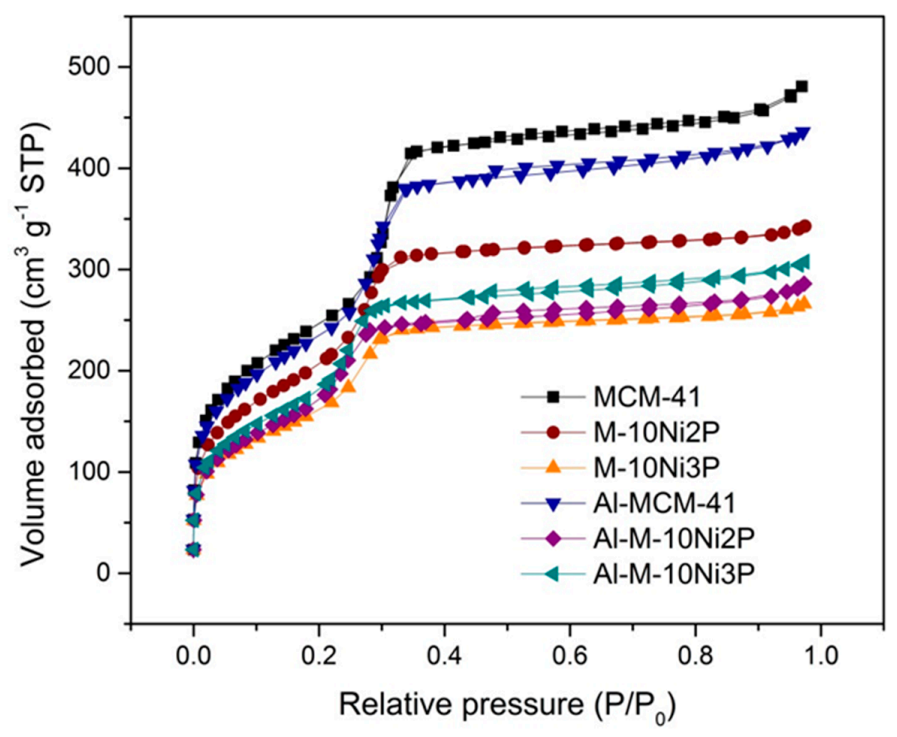

Figure 2. $\mathrm{N}_{2}$ sorption isotherms of the synthesized materials.

Table 1. Textural properties of the synthesized materials.

\begin{tabular}{|c|c|c|c|c|c|}
\hline Materials & $\begin{array}{l}\text { BET Surface Area }{ }^{a} \\
\left(\mathrm{~m}^{2} \mathrm{~g}^{-1}\right)\end{array}$ & $\begin{array}{l}\text { Internal Surface } \\
\text { Area }^{b}\left(\mathrm{~m}^{2} \mathrm{~g}^{-1}\right)\end{array}$ & $\begin{array}{l}\text { External Surface } \\
\text { Area }^{b}\left(\mathrm{~m}^{2} \mathrm{~g}^{-1}\right)\end{array}$ & $\begin{array}{l}\text { Pore Volume } \\
\qquad\left(\mathrm{cm}^{3} \mathrm{~g}^{-1}\right)\end{array}$ & $\begin{array}{c}\text { Pore Diameter }{ }^{c} \\
(\mathrm{~nm})\end{array}$ \\
\hline MCM-41 & 900 & 865 & 71 & 0.68 & 2.43 \\
\hline M-10Ni2P & 771 & 747 & 27 & 0.43 & 2.43 \\
\hline M-10Ni3P & 577 & 552 & 23 & 0.33 & 2.43 \\
\hline Al-MCM-41 & 843 & 767 & 84 & 0.59 & 2.43 \\
\hline Al-M-10Ni2P & 622 & 570 & 48 & 0.35 & 2.43 \\
\hline Al-M-10Ni3P & 643 & 616 & 62 & 0.39 & 2.43 \\
\hline
\end{tabular}

${ }^{\mathrm{a}}$ Calculated from BET method. ${ }^{\mathrm{b}}$ Calculated from t-plot method. ${ }^{\mathrm{c}}$ Calculated from BJH method.

T-plot calculation further revealed that, following the incorporation of nickel phosphide nanoparticles into either supports, the decrease in internal surface area of the materials was more pronounced as compared to the decrease in external surface area. This latter finding indicates that nickel phosphide nanoparticles were relatively well incorporated into the support mesopores. Nevertheless, pore blockage due to agglomerated nickel phosphide nanoparticles and other types of particles, such as unreduced $\mathrm{P}_{4} \mathrm{O}_{12}{ }^{4 \mathrm{TM}}$ species, could also occur [27]. The change in pore volume of the materials exhibited a similar trend to that of the total BET surface area, where the pore volumes of the nickel phosphide incorporated MCM-41 and Al-MCM-41 samples were significantly smaller than those of the undoped counterparts. On the other hand, all samples had similar average pore diameter of $2.43 \mathrm{~nm}$. The latter finding indicates that the structure of the support materials was stable to the reduction process [29].

The morphology of two representative samples-MCM-41 and M-10Ni3P-was characterized by SEM and TEM, and the results are shown in Figure 3. The SEM results show that both MCM-41 
and M-10Ni3P samples exhibited irregular rod shape with smooth surface (Figure 3a,b). Both samples were of similar size, ranging from 0.2-2.4 $\mu \mathrm{m}$. The TEM image of MCM-41 (Figure 3c) illustrates a uniform array of mesoporous channels with a highly ordered hexagonal structure and a mean pore diameter of $\sim 2.0 \mathrm{~nm}$, which is the characteristic of MCM-41 [30] and is in good agreement with the results from the above $\mathrm{N}_{2}$ adsorption-desorption analysis. When nickel phosphides were incorporated into the structure of MCM-41, the nanoparticles appeared to be well dispersed over the MCM-41 support with an average particle size of $5.6 \pm 3.9 \mathrm{~nm}$ (Figure 3d). The fact that the vast majority of these nanoparticles were larger than the average size of the pores indicates that a considerable amount of nickel phosphide nanoparticles was responsible for pore blockage and were otherwise located on the external surface of MCM-41.

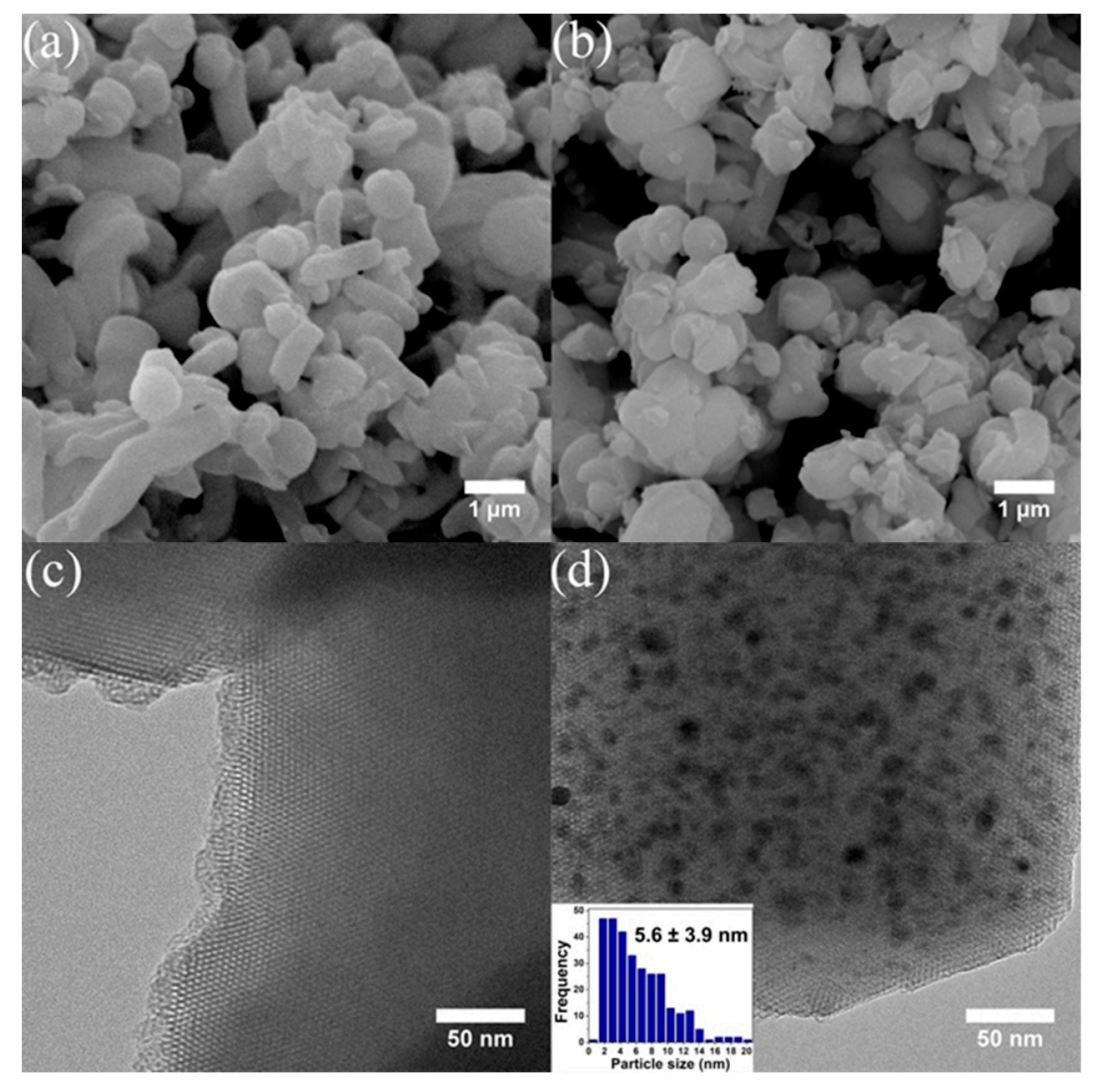

Figure 3. SEM images of MCM-41 (a) and M-10Ni3P (b); TEM images of MCM-41 (c) and M-10Ni3P (d).

Two representative samples containing Al: Al-MCM-41 and Al-M-10Ni3P were characterized by ${ }^{27} \mathrm{Al}$ MAS-NMR in order to determine the coordination environment of aluminum in the samples, and the results are shown in Figure 4. The spectrum of Al-MCM-41 exhibited one resonance at $50.7 \mathrm{ppm}$, indicating that tetrahedral framework aluminum was formed in the mesoporous walls of support [31] and therefore confirming that the post synthesis incorporation of aluminum ions into the MCM-41 structure was successful. The spectrum of the Al-M-10Ni3P showed two strong resonances due to aluminum at 53.2 and $2.1 \mathrm{ppm}$. These resonances indicate that the Al-M-10Ni3P sample contained both tetrahedral framework and octahedral non-framework aluminum, respectively [31]. In addition to the aforementioned resonances, a weak resonance at about 30-40 ppm was also observed, attributable to penta-coordinated aluminum [32]. The presence of penta- and hexa-coordination of aluminum in Al-M-10Ni3P might have resulted from the reduction process in which the temperature was raised to $750{ }^{\circ} \mathrm{C}$ since the use of such a high temperature can potentially cause the formation of these two coordination states of aluminum [33]. 


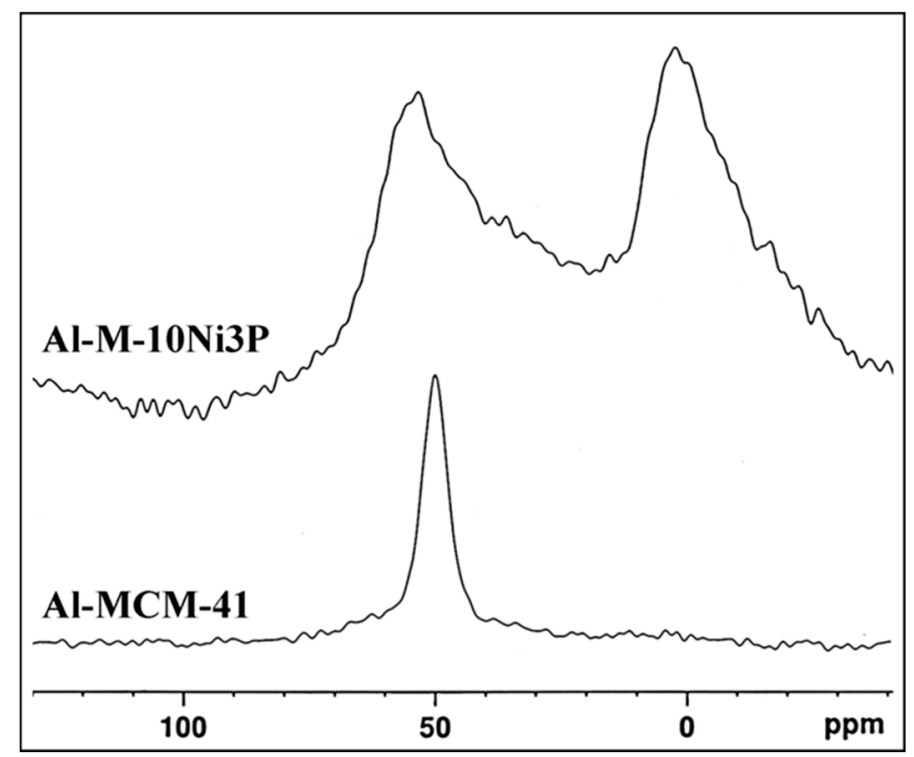

Figure 4. ${ }^{27} \mathrm{Al}$ MAS-NMR spectra of Al-MCM-41 and Al-M-10Ni3P materials.

The contents of nickel and phosphorus in the synthesized samples were determined by ICP-OES, and the results are reported in Table 2. The nickel and phosphorus contents were found to be lower than the corresponding initial amounts used in the synthesis. Specifically, the contents of nickel in all modified samples were in the range of $9.45-9.85 \mathrm{wt} . \%$, a slight decrease (1.5-5.5\%) from the initial amount used of $10 \mathrm{wt} . \%$. As for the contents of phosphorus, the decrease was found to be more pronounced (8.5-14.0\%). The relatively large decrease observed in the latter case could be attributed to the release of volatile phosphorus species, such as $\mathrm{PH}_{3}$ during the reduction step [34]. Consequently, the resulting $\mathrm{Ni} / \mathrm{P}$ ratios of all samples were higher than the corresponding initial ratios used in the synthesis.

Table 2. Elemental contents and total acidity of the synthesized materials.

\begin{tabular}{|c|c|c|c|}
\hline Materials & $\mathrm{Ni}(w \mathrm{w} . \%)^{\mathrm{a}}$ & $P(w t . \%)^{a}$ & Total Acidity $\left(\mu \mathrm{mol} \mathrm{g}{ }^{-1}\right)^{b}$ \\
\hline MCM-41 & - & - & 2 \\
\hline M-10Ni2P & 9.45 & 1.80 & 85 \\
\hline M-10Ni3P & 9.62 & 2.58 & 30 \\
\hline Al-MCM-41 & - & - & 6 \\
\hline Al-M-10Ni2P & 9.59 & 1.83 & 125 \\
\hline Al-M-10Ni3P & 9.85 & 2.62 & 53 \\
\hline
\end{tabular}

The total acidity of the synthesized samples and the strength of their acid sites were characterized using the $\mathrm{NH}_{3}$-TPD technique. The $\mathrm{NH}_{3}$-TPD profiles are shown in Figure 5. According to the $\mathrm{NH}_{3}$-TPD profiles, the $\mathrm{NH}_{3}$ desorption peaks of the undoped MCM-41 and Al-MCM-41 samples were not clearly observed. Nonetheless, the profiles indicate that the total acidity of the undoped Al-MCM-41 sample was higher than that of the undoped MCM-41 sample (Table 2). This finding is likely attributable to the formation of higher concentration of Brönsted acid sites during the substitution of $\mathrm{Al}$ for $\mathrm{Si}$ in the MCM-41 framework [33]. Each $\mathrm{NH}_{3}$-TPD profile of the doped MCM-41 and Al-MCM-41 samples, on the other hand, exhibited at least one distinct desorption peak, indicating that nickel phosphide doping led to the increase of acidity. Specifically, the total acidity of the doped samples was in the range of 30-125 $\mu \mathrm{mol} \mathrm{g}^{-1}$, which is significantly higher than that of the undoped samples $\left(2-6 \mu \mathrm{mol} \mathrm{g}^{-1}\right)$ (Table 2). The high acidity of the doped samples would lead to a higher degree of cellobiose hydrolysis, the details of which will later be discussed. 


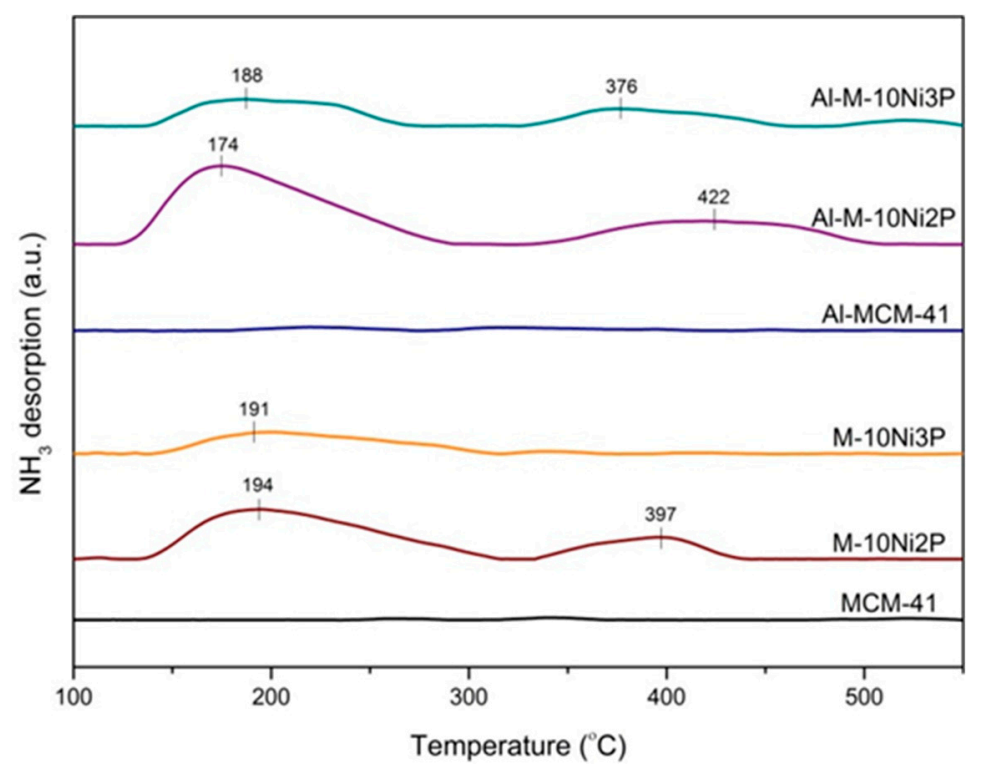

Figure 5. $\mathrm{NH}_{3}$-TPD profiles of the synthesized materials.

As for the strength of the acid sites, the $\mathrm{NH}_{3}$-TPD profiles present two distinct desorption peaks for the M-10Ni2P, Al-M-10Ni2P and Al-M-10N3P samples, suggesting that these doped materials contained acid sites of two different strengths. The lower temperature desorption peaks were observed in the temperature range of $174-194{ }^{\circ} \mathrm{C}$, which can be assigned to the weaker Brönsted acid sites of $\mathrm{P}-\mathrm{OH}$ groups in the unreduced phosphate species [20,35]. It can be observed that the lower temperature desorption peaks for the $\mathrm{M}-10 \mathrm{Ni} 2 \mathrm{P}$ and $\mathrm{Al}-\mathrm{M}-10 \mathrm{Ni} 2 \mathrm{P}$ samples were more intense than those for the $\mathrm{M}-10 \mathrm{Ni3P}$ and Al-M-10Ni3P samples, respectively, even though a higher phosphorus content was initially used for the synthesis of the latter samples. This finding is possibly attributable to the larger presence of the remaining unreduced phosphate species in the M-10Ni2P and Al-M-10Ni2P samples as compared to the $\mathrm{M}-10 \mathrm{Ni} 3 \mathrm{P}$ and $\mathrm{Al}-\mathrm{M}-10 \mathrm{Ni3P}$ samples, respectively, resulting in the higher availability of Brönsted acid of the $\mathrm{P}-\mathrm{OH}$ groups in the former samples. The higher temperature desorption peaks were observed in the temperature range of $376-422{ }^{\circ} \mathrm{C}$ and can be assigned to the stronger Lewis acid sites of the electron-deficient $\mathrm{Ni}^{\delta+}(0<\delta<1)$ species [20,35].

The reducibility of two representative materials, MCM-41 and calcined M-10Ni3P precursor, was investigated by $\mathrm{H}_{2}$-TPR technique. According to the $\mathrm{H}_{2}$-TPR profiles (Figure 6), no obvious reduction peak was observed in the temperature range of $100-800{ }^{\circ} \mathrm{C}$ for the MCM- 41 sample. This finding is consistent with the fact that MCM-41 is a nonreducible oxide [36]. On the other hand, several reduction peaks were observed for the calcined M-10Ni3P precursor sample. First, a minor broad peak at $\sim 300-500{ }^{\circ} \mathrm{C}$ was observed, which can be assigned to the reduction of nickel oxide to nickel (0) [20]. Second, a number of overlapping reduction peaks were also observed over a temperature range of $\sim 500-800{ }^{\circ} \mathrm{C}$. In particular, peaks in the range of $\sim 500-684^{\circ} \mathrm{C}$ can be ascribed to the reduction of the highly stable P-O bonds in nickel phosphate. Also, within this temperature range, the nickel (0) species previously generated at lower temperatures can adsorb and dissociate hydrogen. The dissociated hydrogen species can subsequently spill over to the nickel phosphate and promote the formation of nickel phosphide species [34]. While it is to be noted that the reduction was not complete at the highest temperature of this study $\left(800{ }^{\circ} \mathrm{C}\right)$, the peak observed in the temperature range above $720^{\circ} \mathrm{C}$ can be attributed to the reduction of the excess of phosphate non-associated with nickel [34]. 


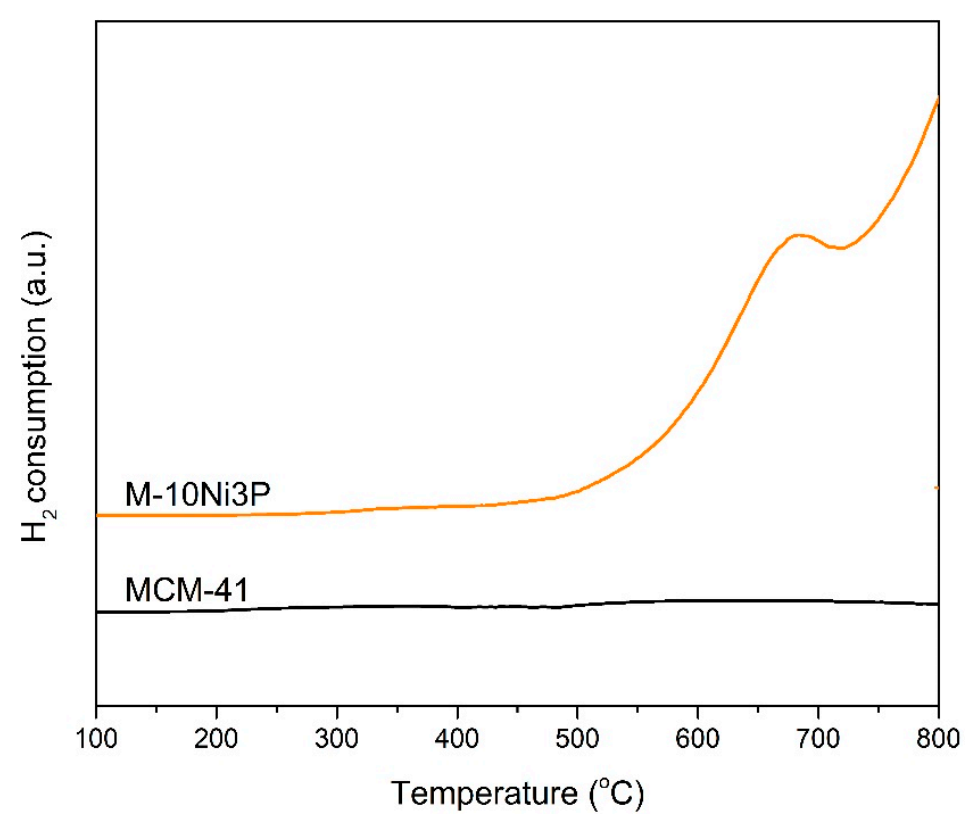

Figure 6. $\mathrm{H}_{2}-\mathrm{TPR}$ profiles of MCM-41 and calcined M-10Ni3P precursor.

\subsection{Catalytic Conversion of Cellobiose to Sorbitol}

The MCM-41- and Al-MCM-41-supported nickel phosphide catalysts were tested for their catalytic performance in the one-pot conversion of cellobiose to sorbitol. In this catalytic reaction, cellobiose molecules had easy access to the active sites located both inside and outside the mesoporous channels of the catalysts. In particular, the calculation by HyperChem showed that the structural size of cellobiose in the samples (length and width of 1.04 and $0.65 \mathrm{~nm}$, respectively) was smaller than the average pore size of the catalysts $(2.43 \mathrm{~nm})$.

To investigate the catalytic performance of the synthesized catalysts, the reaction was performed under the following conditions: $150{ }^{\circ} \mathrm{C}, 3 \mathrm{~h}, 4 \mathrm{MPa}$ of $\mathrm{H}_{2}, 10 \mathrm{~mL}$ of $1 \%$ cellobiose solution, and $0.08 \mathrm{~g}$ of catalyst loading. The control experiments were also performed. First, a blank experiment where no catalyst was used gave $24.6 \%$ conversion of cellobiose, $5.8 \%$ yield of glucose, and no hexitol products. Second, experiments where the undoped MCM- 41 and Al-MCM- 41 materials were used as catalysts were also performed. The updoped MCM- 41 and Al-MCM- 41 materials gave, respectively, $54.8 \%$ and $71.9 \%$ conversion of cellobiose and $16.7 \%$ and $28.0 \%$ yield of glucose. The latter, the only product detected in these reactions, was produced from the hydrolysis of cellobiose catalyzed by acid sites on the surface of the undoped supports. The fact that higher conversion was achieved by Al-MCM-41 than by MCM-41 can primarily be attributed to the higher acid density of the former, which was confirmed by $\mathrm{NH}_{3}$-TPD.

The catalytic performance of the nickel phosphide incorporated catalysts is shown in Figure 7. As compared to the undoped catalysts, the conversion of cellobiose increased to $89.5-95.0 \%$. The fact that the conversion achieved by the M-xNiyP and Al-M-xNiyP catalysts was similarly high indicates that doping the supports with nickel phosphide nanoparticles significantly improved the efficiency of the acid-catalyzed hydrolysis of cellobiose under the reaction conditions used and that the density of acid sites in these catalysts (30-125 $\mu \mathrm{mol} \mathrm{g}^{-1}$ from $\mathrm{NH}_{3}$-TPD) was sufficiently high to convert most of the cellobiose in the reaction into glucose. The distribution of products obtained with the M-xNiyP and Al-M-xNiyP catalysts was also different from that obtained with the undoped counterparts. In particular, in addition to glucose, hexitols (i.e., sorbitol and mannitol) were also obtained.

Despite the above similarity in catalytic performance, the modified catalysts performed differently in terms of sorbitol yield, which can primarily be attributed to the difference in types and amounts of $\mathrm{Ni}$-containing phases present in these catalysts. Specifically, the results indicate that nickel phosphide phases were more active for the hydrogenation of glucose to produce sorbitol than the $\mathrm{Ni}^{0}$ phase. 
For instance, $\mathrm{Al}-\mathrm{M}-10 \mathrm{Ni} 2 \mathrm{P}$, which contained only the $\mathrm{Ni}^{0}$ phase, gave a $18.6 \%$ yield of sorbitol while Al-M-10Ni3P, which contained both the $\mathrm{Ni}^{0}$ and $\mathrm{Ni}_{3} \mathrm{P}$ phases, gave a $25.8 \%$ yield. Further investigation confirmed that the $\mathrm{Ni}_{3} \mathrm{P}$ species had higher catalytic performance in terms of sorbitol yield than the $\mathrm{Ni}^{0}$ species, which is in agreement with a previous report [24]. In particular, $\mathrm{M}-10 \mathrm{Ni2}$, which had a higher $\mathrm{Ni}_{3} \mathrm{P} / \mathrm{Ni}^{0}$ ratio than $\mathrm{Al}-\mathrm{M}-10 \mathrm{Ni3P}$, gave a higher yield of sorbitol than the latter $(33.8 \%$ versus $25.8 \%$ ) even though both catalysts contained the same types of Ni-containing species: $\mathrm{Ni}^{0}$ and $\mathrm{Ni}_{3} \mathrm{P}$.

The $\mathrm{Ni}_{3} \mathrm{P}$ phase, on the other hand, was outperformed by the $\mathrm{Ni}_{12} \mathrm{P}_{5}$ phase for the catalytic production of sorbitol from cellobiose. In particular, by comparing the catalytic performance of the $\mathrm{M}-10 \mathrm{Ni} 2 \mathrm{P}$ and $\mathrm{M}-10 \mathrm{Ni} 3 \mathrm{P}$ catalysts, where the latter contained the $\mathrm{Ni}_{12} \mathrm{P}_{5}$ phase in addition to the phases that were present in both catalysts: $\mathrm{Ni}^{0}$ and $\mathrm{Ni}_{3} \mathrm{P}$, it was found that $\mathrm{M}-10 \mathrm{Ni} 3 \mathrm{P}$ gave a $43.5 \%$ yield of sorbitol while M-10Ni2P gave only a $33.8 \%$ yield.

From the above experimental results, the following order of catalytic performance of the $\mathrm{Ni}$-containing phases for the hydrolytic hydrogenation of cellobiose to sorbitol under the above reaction conditions can be established: $\mathrm{Ni}_{12} \mathrm{P}_{5}>\mathrm{Ni}_{3} \mathrm{P}>\mathrm{Ni}$. Specifically, sorbitol yield was positively related to the relative amount of phosphorus present in the Ni-containing phases. Additionally, it can be established that the higher Brønsted acidity provided by Al in the Al-MCM-41 supported catalysts did not significantly contribute to the catalytic performance in the conversion of cellobiose to sorbitol. A possible explanation is that, under the reaction conditions studied, the density of Brønsted acid in each catalyst of the M-xNiyP and Al-M-xNiyP series was already sufficiently high for the hydrolysis of cellobiose to glucose. The main factor determining the catalytic performance was therefore the composition of phases present in the catalysts, which affected the performance in terms of sorbitol yield. Moreover, while mannitol was also obtained from this reaction system, the sorbitol/mannitol ratio was high $(\geq 10)$. This latter finding suggests that nickel/nickel phosphide-based catalysts are suitable for the selective one-pot conversion of cellobiose to sorbitol.

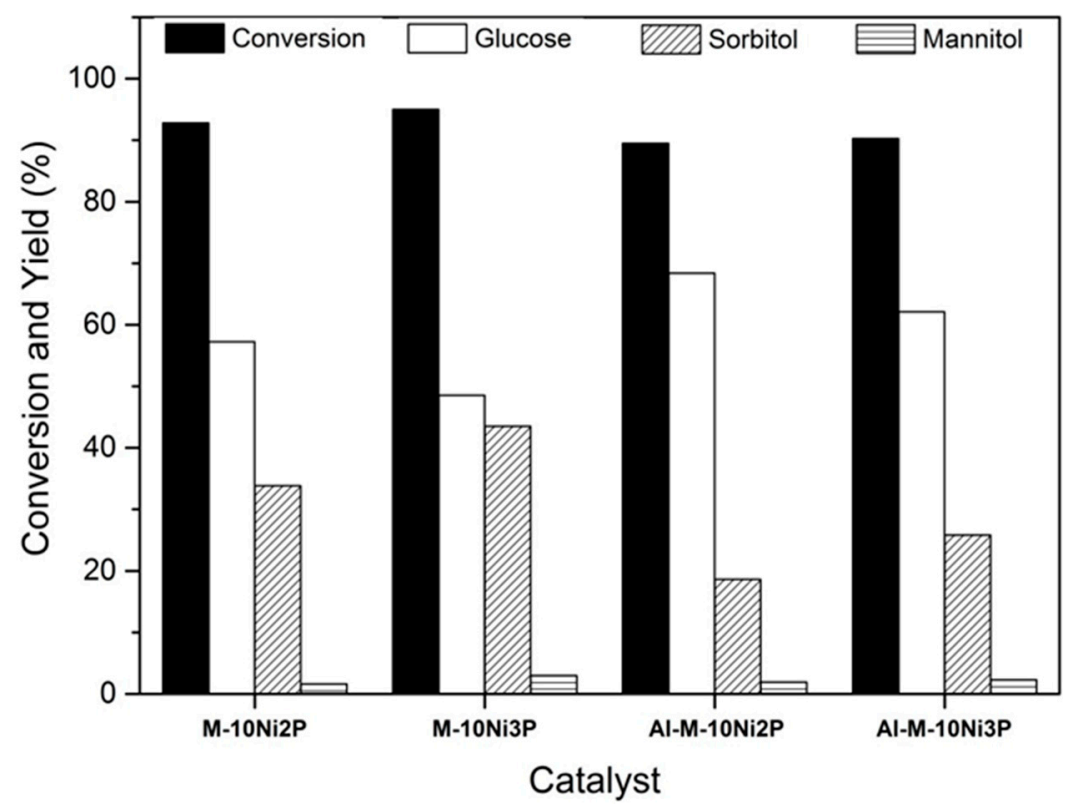

Figure 7. Catalytic performance of $\mathrm{M}-\mathrm{xNiyP}$ and $\mathrm{Al}-\mathrm{M}-\mathrm{xNiyP}$ catalysts for the hydrolytic hydrogenation of cellobiose at $150{ }^{\circ} \mathrm{C}, 3 \mathrm{~h}, 4 \mathrm{MPa}$ of $\mathrm{H}_{2}, 10 \mathrm{~mL}$ of $1 \%$ cellobiose solution, and $0.08 \mathrm{~g}$ of catalyst.

The effect of increasing the reaction temperature on the catalytic performance of the $\mathrm{M}-\mathrm{xNiyP}$ and $\mathrm{Al}-\mathrm{M}-\mathrm{xNiyP}$ catalysts was also investigated. In particular, the reaction temperature was raised to $180^{\circ} \mathrm{C}$, while keeping other reaction conditions constant, and the results are reported in Figure 8 . At $180^{\circ} \mathrm{C}$, all catalysts exhibited high cellobiose conversion (93.3-94.0\%), which was close to that obtained at $150{ }^{\circ} \mathrm{C}(89.5-95.0 \%)$. Nonetheless, a marked improvement in catalytic performance was observed for the subsequent conversion of glucose to sorbitol via hydrogenation. Specifically, at $180^{\circ} \mathrm{C}$, 
the amount of glucose remained in the solution and the sorbitol yield significantly decreased and increased, respectively: less than $7 \%$ glucose remained (versus $48.6-68.4 \%$ at $150{ }^{\circ} \mathrm{C}$ ) and $81.2-87.8 \%$ sorbitol yield was obtained (versus $18.6-43.5 \%$ at $150^{\circ} \mathrm{C}$ ). These findings indicate that temperature also played an important role in the hydrogenation of glucose to sorbitol over the nickel-based catalysts and therefore the performance of both $\mathrm{Ni}^{0}$ and nickel phosphide phases in catalyzing the hydrolytic hydrogenation under the reaction conditions studied can be effectively optimized by controlling the reaction temperature.

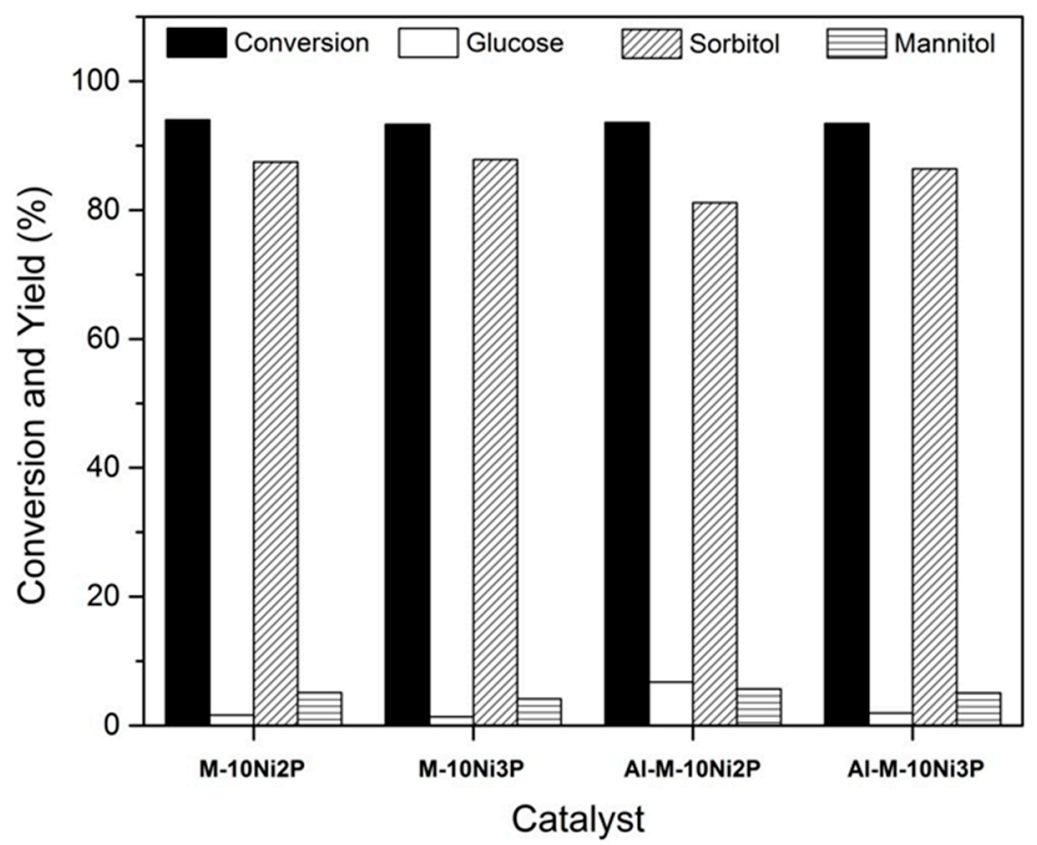

Figure 8. Catalytic performance of $\mathrm{M}-\mathrm{xNiyP}$ and $\mathrm{Al}-\mathrm{M}-\mathrm{xNiyP}$ catalysts for the hydrolytic hydrogenation of cellobiose at $180^{\circ} \mathrm{C}, 3 \mathrm{~h}, 4 \mathrm{MPa}$ of $\mathrm{H}_{2}, 10 \mathrm{~mL}$ of $1 \%$ cellobiose solution, and $0.08 \mathrm{~g}$ of catalyst.

In order to identify the suitable temperature range for the two-step hydrolytic hydrogenation of cellobiose, the conversion was carried out under the aforementioned conditions but with reaction temperature ranging from $140-180^{\circ} \mathrm{C} . \mathrm{M}-10 \mathrm{Ni3P}$, the best performing catalyst in this study, was used as a representative catalyst. The results are shown in Figure 9. It was found that the conversion of cellobiose, which was in the high range of $93.3-96.7 \%$, was not significantly affected by reaction temperature. Nevertheless, reaction temperature had significant effect on product distribution. Notably, increasing the temperature from $140{ }^{\circ} \mathrm{C}$ to $170{ }^{\circ} \mathrm{C}$ led to a large decrease and increase in the contents of glucose and sorbitol, respectively. The effect of reaction temperature on product yields was, however, not linear. In particular, further increasing the temperature from $170{ }^{\circ} \mathrm{C}$ to $180^{\circ} \mathrm{C}$ resulted only in small changes in glucose and sorbitol yields, which were $1.4 \%$ and $87.8 \%$ at $180{ }^{\circ} \mathrm{C}$, respectively. Mannitol yield, like the conversion of cellobiose, was relatively unaffected by reaction temperature. Particularly, the yield was found to be about $4 \%$ or less across the range of temperature studied. Overall, the suitable reaction temperature for the two-step catalytic reaction was $170-180^{\circ} \mathrm{C}$. Under all reaction conditions employed in this study, the carbon balances for the hydrolytic hydrogenation of cellobiose using the $\mathrm{M}-\mathrm{xNiyP}$ and Al-M-xNiyP catalysts were above $98.5 \%$. This finding suggests that the occurrence of side reactions where the formation of degradation byproducts and/or that of coke took place were relatively small. It is to be noted that increasing the temperature beyond $180{ }^{\circ} \mathrm{C}$ might otherwise deteriorate the yield of sorbitol since its decomposition to form lower alcohols such as glycol and 1,2-propanediol can occur under $\mathrm{H}_{2}$ atmosphere [14]. 


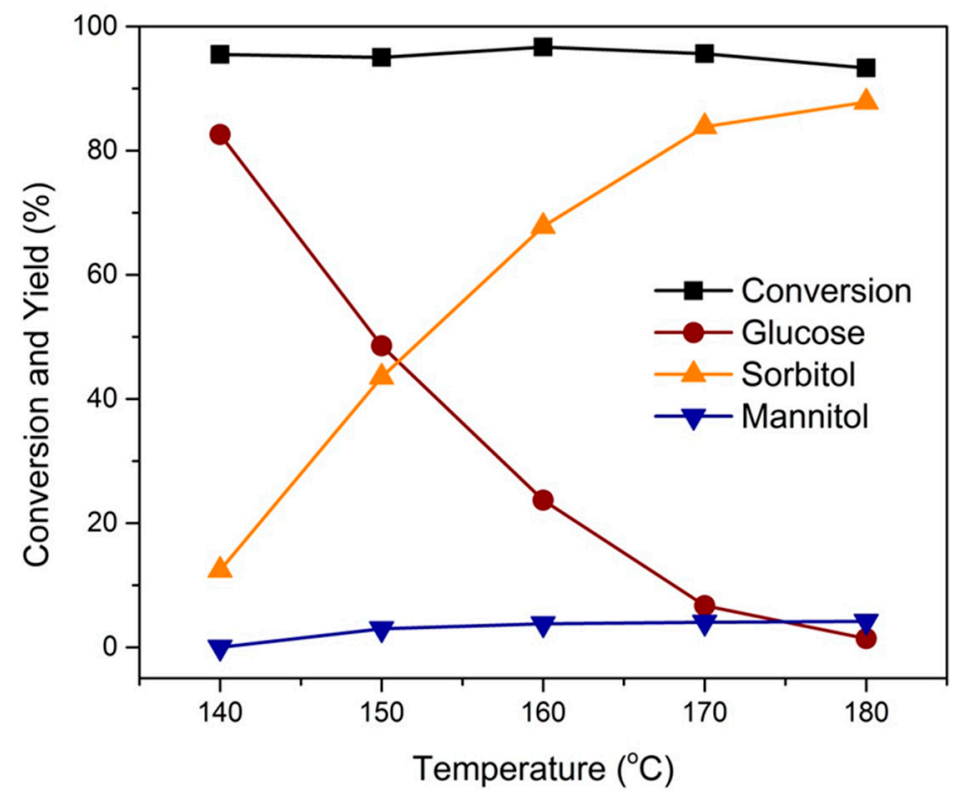

Figure 9. Effect of reaction temperature $\left(140-180^{\circ} \mathrm{C}\right)$ on cellobiose conversion and product distribution in the hydrolytic hydrogenation of cellobiose for $3 \mathrm{~h}$ using $4 \mathrm{MPa}$ of $\mathrm{H}_{2}, 10 \mathrm{~mL}$ of $1 \%$ cellobiose solution, and $0.08 \mathrm{~g}$ of catalyst.

To investigate the catalyst reusability in the hydrolytic hydrogenation of celobiose, $\mathrm{M}-10 \mathrm{Ni} 3 \mathrm{P}$ was used as the representative catalyst for the reaction under the following conditions: $180^{\circ} \mathrm{C}, 3 \mathrm{~h}$, $4 \mathrm{MPa}$ of $\mathrm{H}_{2}, 10 \mathrm{~mL}$ of $1 \%$ cellobiose solution, and $0.08 \mathrm{~g}$ of catalyst loading. The result indicates that, after the first recycling run, the sorbitol yield significantly decreased from $87.8 \%$ to $64.8 \%$ despite the fact that the conversion of cellobiose only decreased from $93.3 \%$ to $91.7 \%$. The overall decrease in catalyst performance can be attributed to the partial leaching of amorphous nickel phosphides at high temperature, which can occur following the transformation of crystalline nickel phosphides to their amorphous forms. An example of this type of leaching can be represented by the following equation [24]:

$$
2 \mathrm{Ni}_{12} \mathrm{P}_{5}+40 \mathrm{H}_{2} \mathrm{O} \rightarrow 24 \mathrm{Ni}+10 \mathrm{H}_{3} \mathrm{PO}_{4}+25 \mathrm{H}_{2}
$$

According to the equation, the leaching process leads to the change of a nickel phosphide phase to the less catalytically active $\mathrm{Ni}^{0}$ phase. Consequently, the sorbitol yield decreased. It can therefore be expected that improving the high-temperature stability in aqueous reactions of the supported nickel phosphide-based catalysts will result in the improvement of overall catalytic performance.

\subsection{Catalytic Mechanism}

The mechanism that provided the bifunctionality of the nickel phosphide catalysts in the hydrolytic hydrogenation of cellobiose comprised primarily of i) the Brönsted acid sites on the surface of the supports (MCM-41 and Al-MCM-41) and those from the $\mathrm{P}-\mathrm{OH}$ groups of the unreduced phosphate species and ii) the nickel sites of nickel phosphides. In particular, the Brönsted acid sites helped drive the hydrolysis of cellobiose by cleaving its $\beta-1,4$ glycosidic bonds (C-O-C) to produce glucose, while the nickel sites helped in the adsorption and dissociation of hydrogen through catalyzing the hydrogenation of glucose to hexitols (i.e., sorbitol and mannitol) [20,37] (Scheme 1). Additionally, the presence of phosphorus in nickel phosphides also induced the change in electron density of the nickel cations and therefore helped facilitate the hydrogen dissociation in the hydrogenation step [38]. 


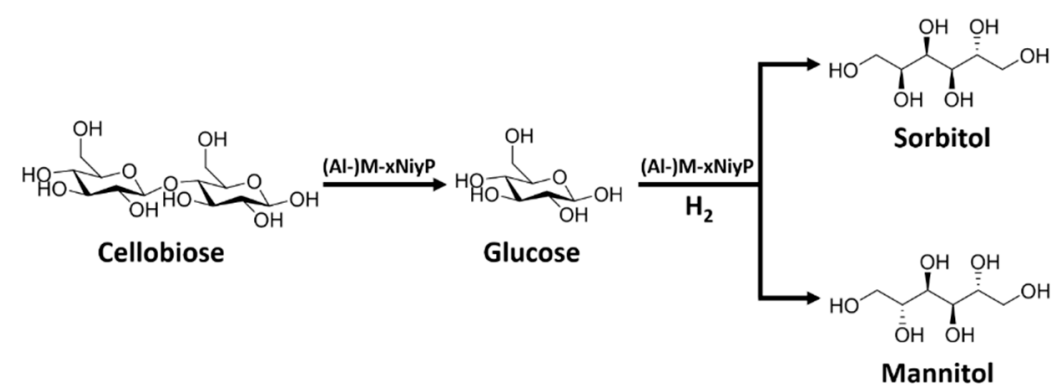

Scheme 1. Hydrolytic hydrogenation of cellobiose to produce hexitols.

In addition to the twoconsecutive reaction pathways mentioned above, the hydrolytic hydrogenation of cellobiose may also involve the hydrogenation of cellobiose to cellobitol followed by the hydrolysis of cellobitol to sorbitol $[10,39]$. However, this alternative pathway was not present under the reaction conditions used in this study, owing to the fact that cellobitol was not detected as an intermediate. As a matter of fact, the catalytic pathways for the hydrolytic hydrogenation of cellbiose can be affected by a number of factors and conditions including reaction temperature, catalyst loading, as well as the presence of mineral acids [39].

\subsection{Comparison of Catalytic Performance of Various Metal-Based Catalysts}

The catalytic performance in the one-pot conversion of cellobiose to sorbitol of the M-10Ni3P catalyst - the most efficient catalyst in this study - was compared to that of several other metal-based catalysts and the results are reported in Table 3. It was found that the M-10Ni3P catalyst showed similar or higher sorbitol yield as compared to other catalysts based on noble metals such as $\mathrm{Pd}, \mathrm{Pt}$, and $\mathrm{Ru}$. Moreover, unlike the system described in this work, a number of other catalytic systems require the addition of a homogeneous acid solution in order to allow the conversion of cellobiose to sorbitol to proceed in one pot as well as to improve the yield of sorbitol.

Table 3. Comparison of catalytic performance of various catalysts for cellobiose conversion to sorbitol.

\begin{tabular}{|c|c|c|c|c|c|c|}
\hline Catalyst & Time (h) & $\begin{array}{l}\text { Temp. } \\
\left({ }^{\circ} \mathrm{C}\right)\end{array}$ & $\begin{array}{c}\text { Pressure of } \\
\mathrm{H}_{2}(\mathrm{MPa})\end{array}$ & $\begin{array}{c}\text { Cellobiose } \\
\text { Conversion }(\%)\end{array}$ & $\begin{array}{c}\text { Sorbitol } \\
\text { Yield (\%) }\end{array}$ & Reference \\
\hline M-10Ni3P & 3 & 150 & 4 & 95.0 & 43.5 & This work \\
\hline M-10Ni3P & 3 & 180 & 4 & 93.3 & 87.8 & This work \\
\hline Pd with pH 2 & 12 & 120 & 4 & 100 & 0 & [13] \\
\hline Pt with pH 2 & 12 & 120 & 4 & 100 & 18.5 & [13] \\
\hline Ru with pH 2 & 12 & 120 & 4 & 100 & 100 & [13] \\
\hline $\mathrm{Ru} / \mathrm{C}$ & 12 & 120 & 4 & 100 & $<1$ & [13] \\
\hline $\mathrm{Ru} / \mathrm{Cs}_{3} \mathrm{PW}_{12} \mathrm{O}_{40}$ & 6 & 140 & 2 & 100 & 86 & [40] \\
\hline $\mathrm{Ru} / \mathrm{Cs}_{2} \mathrm{HPW}_{12} \mathrm{O}_{40}$ & 6 & 140 & 2 & 100 & 93 & [40] \\
\hline $\mathrm{Ru} / \mathrm{C}+0.05$ wt. $\% \mathrm{H}_{3} \mathrm{PO}_{4}$ & 1 & 185 & 3 & n.r. ${ }^{a}$ & 87.1 & [14] \\
\hline 3\%RuNPs/Amberlyst 15 & 5 & 150 & 4 & 100 & 81.6 & [15] \\
\hline
\end{tabular}

\section{Materials and Methods}

\subsection{Materials}

Hexadecyltrimethylammonium bromide (CTAB), tetraethyl orthosilicate (TEOS), ammonia solution (25\%), aluminium isopropoxide, hydrochloric acid and ethanol were purchased from Merck (Darmstadt, Germany). Toluene was purchased from Carlo Erba Reagents (Val de Reuil, France). Ammonium dihydrogen phosphate $\left(\mathrm{NH}_{4} \mathrm{H}_{2} \mathrm{PO}_{4}\right)$ and nitric acid were purchased from Shantou Xilong Chemical Co., Ltd. (Guangdong, China). Nickel (II) nitrate hexahydrate was purchased from Beijing Yili Chemical Co., Ltd. (Beijing, China). Cellobiose was purchased from J\&K Chemical Co., Ltd. (Shanghai, China). Glucose, sorbitol, and mannitol were purchased from Alfa Aesar (Ward Hill, MA, USA). All chemicals were analytical grade reagents and were used without further purification. 


\subsection{Synthesis of Nickel Phosphide Nanoparticles Supported on MCM-41 and Al-MCM-41}

Mesoporous MCM-41 was synthesized by the following procedure: First, $2.4 \mathrm{~g}$ of CTAB was dissolved in $120 \mathrm{~g}$ of deionized water. Then, $10.24 \mathrm{~mL}$ of ammonia solution was added to the above solution and the mixture was stirred for $5 \mathrm{~min}$ at room temperature. After that, $10 \mathrm{~mL}$ of TEOS was added dropwise to the resulting solution under stirring. The mixture was further stirred at room temperature for $24 \mathrm{~h}$ and the resulting product was filtered and washed with ethanol and deionized water until the $\mathrm{pH}$ of the wash solution was 7 . The solid product was then dried at $60^{\circ} \mathrm{C}$ for $12 \mathrm{~h}$ followed by calcination at $550{ }^{\circ} \mathrm{C}$ for $5 \mathrm{~h}$ to obtain MCM-41.

Al-MCM-41 was synthesized by adding $1.0 \mathrm{~g}$ of MCM-41 and a required amount of aluminum isopropoxide in $100 \mathrm{~mL}$ of toluene such that the $\mathrm{Si} / \mathrm{Al}$ molar ratio was 14.1. The mixture was then stirred at room temperature for $12 \mathrm{~h}$. The solid product was filtered and subsequently dried at $100^{\circ} \mathrm{C}$ for $12 \mathrm{~h}$, followed by calcination at $550{ }^{\circ} \mathrm{C}$ for $5 \mathrm{~h}$ to obtain Al-MCM- 41 .

The syntheses of MCM-41 and Al-MCM-41 supported nickel phosphide catalysts were modified from a previous report [24] where two different initial Ni/P ratios were used: a constant nickel loading of $10 \mathrm{wt} . \%$ and varied phosphorus loadings of $2 \mathrm{wt.} \%$ and $3 \mathrm{wt} . \%$. Briefly, the required amounts of nickel (II) nitrate hexahydrate and dihydrogen phosphate were dissolved in $3 \mathrm{~mL}$ of deionized water. A small amount of concentrated $\mathrm{HNO}_{3}$ was added to the mixture as required to obtain a homogeneous solution. The solution was then sonicated for $5 \mathrm{~min}$, followed by the addition of $0.5 \mathrm{~g}$ of MCM- 41 or Al-MCM-41. The mixture was subsequently stirred at room temperature for $16 \mathrm{~h}$ and dried at $60^{\circ} \mathrm{C}$ for $24 \mathrm{~h}$. The resulting solid was then calcined at $550^{\circ} \mathrm{C}$ for $4 \mathrm{~h}$ prior to being reduced in $\mathrm{H}_{2}$ atmosphere at $750{ }^{\circ} \mathrm{C}$ for $2 \mathrm{~h}$. Finally, the product was cooled to room temperature and passivated in a $0.5 \% \mathrm{O}_{2} / \mathrm{Ar}$ flow for $3 \mathrm{~h}$. The resulting MCM-41 and Al-MCM-41 supported nickel phosphide catalysts are denoted as M-xNiyP and Al-M-xNiyP, respectively, where $\mathrm{x}$ and $\mathrm{y}$ represent the initial wt.\% loadings of nickel and phosphorus, respectively.

\subsection{Materials Characterization}

The crystalline phases of the prepared materials were identified by X-ray diffractometer (XRD) (Rigaku D/MaX-2200 Ultima-plus, Tokyo, Japan) with a Cu K $\alpha$ X-ray source of wavelength $1.5418 \AA$ operated at $40 \mathrm{kV}$ and $30 \mathrm{~mA}$. Low- and high-angle XRD patterns were recorded in the ranges of $1.5^{\circ}$ to $6.0^{\circ}$ and $20.0^{\circ}$ to $80.0^{\circ}$, respectively, with a scanning rate of $5^{\circ} \mathrm{min}^{-1}$. The textural properties of the materials were analyzed by $\mathrm{N}_{2}$ adsorption-desorption with a BELSORP-mini-II apparatus (BEL Inc., Osaka, Japan). The surface area was calculated according to the Brunauer-Emmett-Teller (BET) method and the pore volume and pore size were calculated according to the Barrett-Joyner-Halenda $(\mathrm{BJH})$ method. The position of aluminum ions in the lattice was determined by ${ }^{27} \mathrm{Al}$-magnetic angle spinning-nuclear magnetic resonance spectrometer $\left({ }^{27} \mathrm{Al}\right.$ MAS-NMR, Bruker Avance DPX $300 \mathrm{MHz}$, Karlsruhe, Germany) operated at $78 \mathrm{MHz}$. The morphology and particle size of the materials were analyzed by transmission electron microscope (TEM, JEOL JEM-2100, Peabody, MA, USA) and scanning electron microscope (SEM, JSM-5410 LV, Peabody, MA, USA). The acidity of the synthesized materials was measured by temperature programmed desorption of ammonia $\left(\mathrm{NH}_{3}-\mathrm{TPD}\right)$ using a Micromeritics AutoChem II 2920 chemisorption analyzer. Before acidity measurement, each sample was pretreated under helium flow $\left(50 \mathrm{~mL} \mathrm{~min}^{-1}\right)$ at $500{ }^{\circ} \mathrm{C}$ for $5 \mathrm{~h}$. Each sample was then saturated with 10 vol. $\% \mathrm{NH}_{3}\left(10 \mathrm{~mL} \mathrm{~min}^{-1}\right)$ and the weakly adsorbed $\mathrm{NH}_{3}$ was removed. After that, each sample was heated from $50{ }^{\circ} \mathrm{C}$ to $550{ }^{\circ} \mathrm{C}$ at a rate of $10{ }^{\circ} \mathrm{C} \mathrm{min}{ }^{-1}$. The reducibility of the catalyst precursors was measured by temperature-programmed reduction $\left(\mathrm{H}_{2}\right.$-TPR) using a Micrometrics Chemisorbs 2750 automatic system. In the procedure, $0.1 \mathrm{~g}$ of each sample was carried out in a quartz U-tube reactor. The reduction was conducted in $10 \% \mathrm{H}_{2}$ in Ar with a flow rate of $25 \mathrm{~mL} \mathrm{~min}{ }^{-1}$ and a heating rate of $10^{\circ} \mathrm{C} \mathrm{min}^{-1}$. The consumption of hydrogen was determined by a thermal conductivity detector (TCD). Nickel and phosphorus contents in the materials were measured by inductively coupled plasma optical emission spectrophotometer (ICP-OES) (Perkin Elmer Optima 2100, Waltham, MA, USA) after acid digestion of the materials. 


\subsection{Catalytic Cellobiose Conversion and Product Analysis}

The conversion of cellobiose was performed in a Teflon-lined stainless-steel autoclave. Unless otherwise stated, the reaction was performed as follows: $10 \mathrm{~mL}$ of $1 \%$ cellobiose solution and $0.08 \mathrm{~g}$ of catalyst were added into the reactor. The reactor was purged four times with $\mathrm{H}_{2}$ and pressurized with $4 \mathrm{MPa}$ of $\mathrm{H}_{2}$ at room temperature. The catalytic reaction was then performed at a desired temperature for $3 \mathrm{~h}$ with a stirring rate of $750 \mathrm{rpm}$. The autoclave was subsequently cooled down to room temperature, and the solid catalyst was separated by vacuum filtration. The liquid products were analyzed using a high-performance liquid chromatography (HPLC) (Shimadzu LC-20AD, Kyoto, Japan) connected with refractive index detector using deionized water as mobile phase with the flow rate of $60 \mathrm{~mL} / \mathrm{min}$ and the oven temperature of $70.0{ }^{\circ} \mathrm{C}$. For the quantification of the remaining cellobiose and the products present in the reaction mixture, external standard calibrations of pure compounds were performed under the same conditions as those used for the analysis of liquid products. The cellobiose conversion and product yield were calculated as follows:

$$
\begin{gathered}
\text { Conversion }(\%)=\frac{\left(\mathrm{mol}_{\text {cellobiose before reaction }}-\mathrm{mol}_{\text {cellobiose after reaction }}\right)}{\mathrm{mol}_{\text {cellobiose before reaction }}} \times 100 \\
\text { Yield }(\%)=\frac{\mathrm{mol}_{\text {carbon in each product }}}{\mathrm{mol}_{\text {carbon in cellobiose before reaction }}} \times 100
\end{gathered}
$$

\section{Conclusions}

The synthesized MCM-41- and Al-MCM-4-supported nickel phosphide nanomaterials were highly efficient bifunctional heterogeneous catalysts for the one-pot conversion of cellobiose to sorbitol. The bifunctionality was achieved by combining acid sites originating mainly from $\mathrm{P}-\mathrm{OH}$ groups of the unreduced phosphate species and metallic sites created by Ni species, which participated in catalyzing the hydrolysis of cellobiose to glucose and the hydrogenation of glucose to sorbitol, respectively. Under the reaction conditions of $150{ }^{\circ} \mathrm{C}, 3 \mathrm{~h}$, and $4 \mathrm{MPa}$ of $\mathrm{H}_{2}$, the acidity of the catalysts was sufficient for catalyzing the hydrolysis process where high cellobiose conversion of $89.5-95.0 \%$ was obtained. Nonetheless, the catalytic performance in the hydrogenation process varied greatly with the presence of Ni-containing species in the catalysts, where sorbitol yield was positively related to the relative abundance of phosphorus-rich species: $\mathrm{Ni}_{12} \mathrm{P}_{5}>\mathrm{Ni}_{3} \mathrm{P}>\mathrm{Ni}$. Sorbitol yield was also found to depend on the reaction temperature, where the yield produced by the best catalyst in this study more than doubled (from 43.5 to $87.8 \%$ ), without significant formation of undesired products, when the temperature was increased from 150 to $180{ }^{\circ} \mathrm{C}$. Due to the environmental friendliness, cost-effectiveness and high efficiency offered by the bifunctional heterogeneous catalytic system described in this work, it has wide potential applications in catalysis and proved to be a promising candidate to replace catalytic systems based on noble metals.

Author Contributions: Conceptualization, W.A., H.L. and D.N.T.; methodology, W.A., K.E., D.J., A.P., and D.N.T.; investigation, W.A., K.E., D.J., and A.P.; writing-original draft preparation, W.A., K.E., and D.J.; writing一review and editing, T.T., H.L., and D.N.T.

Funding: This research was funded by the CU-56-912-AM, International Research Integration: Chula Research Scholar, Ratchadaphiseksomphot Endowment Fund, the Post-doctoral Fellowship, and the Research Grant for New scholar CU Researcher's Project from the Ratchadaphiseksomphot Endowment Fund of Chulalongkorn University.

Conflicts of Interest: The authors declare no conflicts of interest.

\section{References}

1. Yabushita, M.; Kobayashi, H.; Fukuoka, A. Catalytic transformation of cellulose into platform chemicals. Appl. Catal. B 2014, 145, 1-9. [CrossRef]

2. Besson, M.; Gallezot, P.; Pinel, C. Conversion of biomass into chemicals over metal catalysts. Chem. Rev. 2014, 114, 1827-1870. [CrossRef] [PubMed] 
3. Kobayashi, H.; Fukuoka, A. Synthesis and utilisation of sugar compounds derived from lignocellulosic biomass. Green Chem. 2013, 15, 1740-1763. [CrossRef]

4. Dhepe, P.L.; Fukuoka, A. Cellulose conversion under heterogeneous catalysis. ChemSusChem 2008, 1, 969-975. [CrossRef] [PubMed]

5. Rinaldi, R.; Palkovits, R.; Schüth, F. Depolymerization of cellulose using solid catalysts in ionic liquids. Angew. Chem. Int. Ed. 2008, 47, 8047-8050. [CrossRef] [PubMed]

6. Xue, L.; Cheng, K.; Zhang, H.; Deng, W.; Zhang, Q.; Wang, Y. Mesoporous h-zsm-5 as an efficient catalyst for conversions of cellulose and cellobiose into methyl glucosides in methanol. Catal. Today 2016, 274, 60-66. [CrossRef]

7. Hsu, W.-H.; Lee, Y.-Y.; Peng, W.-H.; Wu, K.C.W. Cellulosic conversion in ionic liquids (ils): Effects of $\mathrm{h} 2 \mathrm{o} /$ cellulose molar ratios, temperatures, times, and different ils on the production of monosaccharides and 5-hydroxymethylfurfural (hmf). Catal. Today 2011, 174, 65-69. [CrossRef]

8. An, D.; Ye, A.; Deng, W.; Zhang, Q.; Wang, Y. Selective conversion of cellobiose and cellulose into gluconic acid in water in the presence of oxygen, catalyzed by polyoxometalate-supported gold nanoparticles. Chem. Eur. J. 2012, 18, 2938-2947. [CrossRef]

9. Zhang, Y.; Wang, A.; Zhang, T. A new 3d mesoporous carbon replicated from commercial silica as a catalyst support for direct conversion of cellulose into ethylene glycol. Chem. Commun. 2010, 46, 862-864. [CrossRef]

10. Deng, W.; Liu, M.; Tan, X.; Zhang, Q.; Wang, Y. Conversion of cellobiose into sorbitol in neutral water medium over carbon nanotube-supported ruthenium catalysts. J. Catal. 2010, 271, 22-32. [CrossRef]

11. Zhang, J.; Li, J.-B.; Wu, S.-B.; Liu, Y. Advances in the catalytic production and utilization of sorbitol. Ind. Eng. Chem. Res. 2013, 52, 11799-11815. [CrossRef]

12. Fukuoka, A.; Dhepe, P.L. Catalytic conversion of cellulose into sugar alcohols. Angew. Chem. Int. Ed. Engl. 2006, 45, 5161-5163. [CrossRef] [PubMed]

13. Yan, N.; Zhao, C.; Luo, C.; Dyson, P.J.; Liu, H.; Kou, Y. One-step conversion of cellobiose to c6-alcohols using a ruthenium nanocluster catalyst. J. Am. Chem. Soc. 2006, 128, 8714-8715. [CrossRef] [PubMed]

14. Zhang, J.; Wu, S.; Li, B.; Zhang, H. Direct conversion of cellobiose into sorbitol and catalyst deactivation mechanism. Catal. Commun. 2012, 29, 180-184. [CrossRef]

15. Almeida, J.M.A.R.; Da Vià, L.; Demma Carà, P.; Carvalho, Y.; Romano, P.N.; Peña, J.A.O.; Smith, L.; Sousa-Aguiar, E.F.; Lopez-Sanchez, J.A. Screening of mono- and bi-functional catalysts for the one-pot conversion of cellobiose into sorbitol. Catal. Today 2017, 279, 187-193. [CrossRef]

16. Geboers, J.; Van de Vyver, S.; Carpentier, K.; Jacobs, P.; Sels, B. Efficient hydrolytic hydrogenation of cellulose in the presence of ru-loaded zeolites and trace amounts of mineral acid. Chem. Commun. (Camb.) 2011, 47, 5590-5592. [CrossRef]

17. Kusserow, B.; Schimpf, S.; Claus, P. Hydrogenation of glucose to sorbitol over nickel and ruthenium catalysts. Adv. Synth. Catal. 2003, 345, 289-299. [CrossRef]

18. Zhang, B.; Li, X.; Wu, Q.; Zhang, C.; Yu, Y.; Lan, M.; Wei, X.; Ying, Z.; Liu, T.; Liang, G.; et al. Synthesis of $\mathrm{ni} /$ mesoporous zsm-5 for direct catalytic conversion of cellulose to hexitols: Modulating the pore structure and acidic sites via a nanocrystalline cellulose template. Green Chem. 2016, 18, 3315-3323. [CrossRef]

19. Zhang, J.; Wu, S.; Liu, Y.; Li, B. Hydrogenation of glucose over reduced ni/cu/al hydrotalcite precursors. Catal. Commun. 2013, 35, 23-26. [CrossRef]

20. Yang, Y.; Chen, J.; Shi, H. Deoxygenation of methyl laurate as a model compound to hydrocarbons on ni2p/sio2, ni2p/mcm-41, and ni2p/sba-15 catalysts with different dispersions. Energy Fuels 2013, 27, 3400-3409. [CrossRef]

21. Koranyi, T.; Vit, Z.; Poduval, D.; Ryoo, R.; Kim, H.; Hensen, E. Sba-15-supported nickel phosphide hydrotreating catalysts. J. Catal. 2008, 253, 119-131. [CrossRef]

22. Oyama, S.; Lee, Y. The active site of nickel phosphide catalysts for the hydrodesulfurization of 4,6-dmdbt. J. Catal. 2008, 258, 393-400. [CrossRef]

23. Alexander, A.M.; Hargreaves, J.S. Alternative catalytic materials: Carbides, nitrides, phosphides and amorphous boron alloys. Chem. Soc. Rev. 2010, 39, 4388-4401. [CrossRef] [PubMed]

24. Yang, P.; Kobayashi, H.; Hara, K.; Fukuoka, A. Phase change of nickel phosphide catalysts in the conversion of cellulose into sorbitol. ChemSusChem 2012, 5, 920-926. [CrossRef]

25. Mathew, A.; Parambadath, S.; Kim, S.Y.; Ha, H.M.; Ha, C.-S. Diffusion mediated selective adsorption of zn2+ from artificial seawater by mcm-41. Microporous Mesoporous Mater. 2016, 229, 124-133. [CrossRef] 
26. Song, H.; Wang, J.; Wang, Z.; Song, H.; Li, F.; Jin, Z. Effect of titanium content on dibenzothiophene HDS performance over $\mathrm{Ni}_{2} \mathrm{P} / \mathrm{Ti}-\mathrm{MCM}-41$ catalyst. J. Catal. 2014, 311, 257-265. [CrossRef]

27. Wang, R.; Smith, K.J. The effect of preparation conditions on the properties of high-surface area ni2p catalysts. Appl. Catal. A 2010, 380, 149-164. [CrossRef]

28. Rouquerol, J.; Avnir, D.; Fairbridge, C.W.; Everett, D.H.; Haynes, J.M.; Pernicone, N.; Ramsay, J.D.F.; Sing, K.S.W.; Unger, K.K. Recommendations for the characterization of porous solids (technical report). Pure Appl. Chem. 1994, 66, 1739-1758. [CrossRef]

29. Kadi, M.W.; Hameed, A.; Mohamed, R.M.; Ismail, I.M.I.; Alangari, Y.; Cheng, H.-M. The effect of pt nanoparticles distribution on the removal of cyanide by tio2 coated al-mcm-41 in blue light exposure. Arab. J. Chem. 2016. [CrossRef]

30. Kresge, C.T.; Leonowicz, M.E.; Roth, W.J.; Vartuli, J.C.; Beck, J.S. Ordered mesoporous molecular sieves synthesized by a liquid-crystal template mechanism. Nature 1992, 359, 710. [CrossRef]

31. Gokulakrishnan, N.; Pandurangan, A.; Somanathan, T.; Sinha, P.K. Uptake of decontaminating agent from aqueous solution: A study on adsorption behaviour of oxalic acid over al-mcm-41 adsorbents. J. Porous Mater. 2010, 17, 763-771. [CrossRef]

32. Chen, S.; Li, J.; Zhang, Y.; Zhao, Y.; Liew, K.; Hong, J. Ru catalysts supported on al-sba-15 with high aluminum content and their bifunctional catalytic performance in fischer-tropsch synthesis. Catal. Sci. Technol. 2014, 4, 1005-1011. [CrossRef]

33. Mokaya, R. Post-synthesis grafting of al onto mcm-41. Chem. Commun. 1997, 22, 2185-2186. [CrossRef]

34. Yang, Y.; Ochoa-Hernández, C.; Pizarro, P.; de la Peña O'Shea, V.A.; Coronado, J.M.; Serrano, D.P. Influence of the ni/p ratio and metal loading on the performance of nixpy/sba-15 catalysts for the hydrodeoxygenation of methyl oleate. Fuel 2015, 144, 60-70. [CrossRef]

35. Wu, S.-K.; Lai, P.-C.; Lin, Y.-C. Atmospheric hydrodeoxygenation of guaiacol over nickel phosphide catalysts: Effect of phosphorus composition. Catal. Lett. 2014, 144, 878-889. [CrossRef]

36. Prins, R. Hydrogen spillover. Facts and fiction. Chem. Rev. 2012, 112, 2714-2738. [CrossRef] [PubMed]

37. Ding, L.N.; Wang, A.Q.; Zheng, M.Y.; Zhang, T. Selective transformation of cellulose into sorbitol by using a bifunctional nickel phosphide catalyst. ChemSusChem 2010, 3, 818-821. [CrossRef] [PubMed]

38. Berenguer, A.; Sankaranarayanan, T.M.; Gómez, G.; Moreno, I.; Coronado, J.M.; Pizarro, P.; Serrano, D.P. Evaluation of transition metal phosphides supported on ordered mesoporous materials as catalysts for phenol hydrodeoxygenation. Green Chem. 2016, 18, 1938-1951. [CrossRef]

39. Negahdar, L.; Oltmanns, J.U.; Palkovits, S.; Palkovits, R. Kinetic investigation of the catalytic conversion of cellobioseto sorbitol. Appl. Catal. B 2014, 147, 677-683. [CrossRef]

40. Liu, M.; Deng, W.; Zhang, Q.; Wang, Y.; Wang, Y. Polyoxometalate-supported ruthenium nanoparticles as bifunctional heterogeneous catalysts for the conversions of cellobiose and cellulose into sorbitol under mild conditions. Chem. Commun. (Camb.) 2011, 47, 9717-9719. [CrossRef]

(C) 2019 by the authors. Licensee MDPI, Basel, Switzerland. This article is an open access article distributed under the terms and conditions of the Creative Commons Attribution (CC BY) license (http:/ / creativecommons.org/licenses/by/4.0/). 